\title{
Vitamins and Minerals in Four Traditional Garlic Ecotypes (Allium sativum L.) from Italy: An Example of Territorial Biodiversity
}

\author{
Loretta Gambelli, Stefania Marconi, Alessandra Durazzo $\mathbb{1}$, Emanuela Camilli $\mathbb{\complement}$, Altero Aguzzi, Paolo Gabrielli, \\ Luisa Marletta $\mathbb{1}$ and Silvia Lisciani *(1)
}

check for updates

Citation: Gambelli, L.; Marconi, S.; Durazzo, A.; Camilli, E.; Aguzzi, A.; Gabrielli, P.; Marletta, L.; Lisciani, S Vitamins and Minerals in Four Traditional Garlic Ecotypes (Allium sativum L.) from Italy: An Example of Territorial Biodiversity. Sustainability 2021, 13, 7405. https://doi.org/ $10.3390 /$ su13137405

Academic Editors: Bernhard Huchzermeyer and Marc A. Rosen

Received: 17 May 2021

Accepted: 29 June 2021

Published: 1 July 2021

Publisher's Note: MDPI stays neutral with regard to jurisdictional claims in published maps and institutional affiliations.

Copyright: (c) 2021 by the authors. Licensee MDPI, Basel, Switzerland. This article is an open access article distributed under the terms and conditions of the Creative Commons Attribution (CC BY) license (https:// creativecommons.org/licenses/by/ $4.0 /)$.
Consiglio per la Ricerca in Agricoltura e 1'Analisi dell'Economia Agraria-Centro di Ricerca, CREA-Alimenti e Nutrizione, Via Ardeatina 546, 00178 Rome, Italy; loretta.gambelli@crea.gov.it (L.G.); stefania.marconi@crea.gov.it (S.M.); alessandra.durazzo@crea.gov.it (A.D.); emanuela.camilli@crea.gov.it (E.C.); altero.aguzzi@crea.gov.it (A.A.); paolo.gabrielli@crea.gov.it (P.G.); luisa.francesca.marletta@gmail.com (L.M.)

* Correspondence: silvia.lisciani@crea.gov.it; Tel.: +39-06-51494-652

\begin{abstract}
Garlic (Allium satioum L.) is one of the most important food products in the world and an ancient and widespread medicinal herb. It is rich in minerals and vitamins, which are both essential nutrients for human health. This study was carried out on four traditional landraces of garlic: Rosso di Sulmona, Rosso di Proceno, Bianco Piacentino, and Rosso di Castelliri, all cultivated with the same agricultural practices in two different areas of the Lazio region. The aim was to study the effects of both production soil and genetic characteristics on the concentrations of certain micronutrients in these garlic bulbs. The content of minerals and trace elements $(\mathrm{Ca}, \mathrm{K}, \mathrm{P}, \mathrm{mg}, \mathrm{Na}, \mathrm{Fe}$, $\mathrm{Zn}, \mathrm{Cu}, \mathrm{Mn}$ ) was determined via ICP plasma after liquid washing. Water-soluble vitamins (riboflavin, niacin, thiamine, B6, vitamin C) were evaluated using an HPLC and UV detector. Among the minerals identified, potassium was most represented, with a value ranging between 645 and $1057 \mathrm{mg} / 100 \mathrm{~g}$ d.w., whose content is influenced by the interaction between cultivars and cultivation area, suggesting that pedoclimatic and genetic characteristics determine this content. Among vitamins, vitamin $\mathrm{C}$ was found to be most represented, with an amount that varied from 9.7 to $15.6 \mathrm{mg} / 100 \mathrm{~g}$ f.w. and did not depend on the cultivar or the geographical area. Among the B vitamins, the most abundant was vitamin B6, the maximum content of which was found in the Rosso di Castelliri cultivar grown in Viterbo (2.04 mg/100 g f.w.). Its concentration is influenced by the cultivar and the soil and their interaction. The results obtained showed good levels of essential micronutrients and highlighted that for some of them, the effect of soil typology is expressed in the presence of specific characteristics linked to the genotype.
\end{abstract}

Keywords: Italian garlic; minerals; vitamins

\section{Introduction}

Fruits and vegetables play an important role in human health, as they contain important essential components such as dietary fiber, vitamins, minerals, and phytochemicals, all of which may reduce the risk of chronic diseases [1,2] and improve the immune system factor currently of great importance [3,4]. Minerals and vitamins are considered to be micronutrients, and they are not aimed at the production of energy, but act mainly as coenzymes and cofactors [5-7]. They are necessary for the functioning and maintenance of the human organism, which is not able to synthesize them; therefore, it is necessary to acquire them through an adequate, balanced, and varied diet [8-10]. Micronutrients interact with each other to regulate biological processes, and they are very important because, even in small quantities, they work together to (i) regulate energy metabolism, nerve function, and muscle contraction; (ii) regulate oxidative function; (iii) maintain bone and blood health; (iv) control water and electrolyte balance; and (v) help immune 
function [10-14]. An appropriate diet is necessary to provide humans with vitamins and minerals, while a low intake of healthy foods and an unbalanced diet can lead to mineral deficiencies - currently a widespread issue in at-risk population groups $[8,15,16]$-and, at the same time, to an overuse of dietary supplements or fortified foods, which is growing rapidly [17].

Moreover, the characterization of compounds of nutritional and nutraceutical nature in the different ecotypes of most consumed foods allows the maintenance of a rich food biodiversity and ensures diet quality, especially in vulnerable populations $[18,19]$. Agricultural crops are the primary source of minerals and vitamins, so micronutrientrelated malnutrition can be solved by increasing the consumption of vegetable products [8].

Garlic (Allium satioum L.) belongs to the plant family Amaryllidaceae and it is one of the most important bulb crops [20]. Native to Central Asia, it is now cultivated worldwide. Garlic has been appreciated since ancient times for its aroma and flavor, which make it suitable for consumption in numerous recipes around the world [21,22]. The first mention of garlic can be traced back to an Egyptian papyrus, the Codex Ebers, dating from 1550 BC, containing hundreds of recipes used, for instance, as a therapeutic cure for headaches and insect bites, and as a painkiller [23]. In fact, in addition to the use of garlic as a food product, it is also known as a medicinal plant; garlic has been used for healing a wide variety of disorders, including leprosy, diarrhea, constipation, asthma, fever, and infection $[24,25]$. The benefits associated with its consumption are attributed to the presence of different functional compounds in it. The synergistic interactions between all the components, vitamins, saponins, and moderate levels of carotenoids contribute to provide the observed health benefits of garlic [21,26]. The advantages attributed to garlic consumption should also include the high fructooligo-/polysaccharide (FOS) content, responsible for its prebiotic activity, together with dietary fiber [27]. In recent years, many researchers have demonstrated various significant biological functions of garlic, including anticancer, cardiovascular protective, anti-inflammatory, and immune modulatory [28-32]. In particular, the wide variety of dietary and medicinal functions of garlic can be attributed to its oil-soluble organosulfur compounds, which are also the main factors responsible for its characteristic flavor and taste [21,31]. The organosulfur compounds of garlic bulbs are a major source of sulfur in the human diet [33-35]. Garlic also contains a decent percentage of sodium, potassium, and magnesium, as well as vitamins, such as C and B [36,37]. Most of the studies present in the literature addressed "commercial" garlic samples, but its particular type of reproduction (agamic) has favored the development and diffusion of numerous local ecotypes that were adapted to different climates and soils [38]. Despite the fact that garlic has been propagated asexually with cloves in many areas of the world by farmers, there is a great diversity in its morphological and agronomic characteristics, mostly due to the existence of various ecotypes that have been cultivated in the same areas for a long time, resulting in the accumulation of natural mutations [39-41].

The genotype significantly affects the chemical composition of garlic bulbs, as well as their growing conditions [34-41]. The quality and fertility of the soil have a direct influence on the levels of nutrients in food crops, in particular on micronutrients. Many factors, such as rainfall, sunshine, temperature [42-44], species, and soil characteristics, including mineral composition and bioavailability, crop systems, and fertilization practices, play critical roles in plant mineral uptake, affecting the morphology, physiology, and nutritional quality [33,43-46]. Therefore, cultivation in selected areas can be used to optimize the content of compounds and, consequently, the quality of the final product [34].

Accordingly, differences in geography and farming conditions may determine variations in mineral content for certain plant species. In addition, fertilizer application rates and soil properties may have a significant effect on the mineral composition of garlic bulbs [41]. In this regard, as reported by Naruka and Dhaka [47], nitrogen fertilization has a positive influence on the $\mathrm{N}, \mathrm{P}, \mathrm{K}$, and $\mathrm{S}$ contents of the bulb, due to the improved nutritional environment both in the root zone and the plant system. An increased availability of nutrients in 
the root zone, coupled with increased metabolic activity at the cellular level, might increase the nutrient uptake and accumulation in the vegetative plant parts [46,48-51].

Despite the importance of knowledge of close linkage between the nutritional profile of local products and territory and cultivation practices [52], food composition data on Italian-specific landraces are still scarce, and studies are incomplete, especially regarding information on the amounts of vitamins. The identification and highlighting of the chemical properties of the landraces compared with "commercial" varieties may represent an added value of the product to better address the consumer preference $[27,53]$ and stimulate cultivation, thus contributing to the protection of this biodiversity by promoting its conservation [53]. The valorization of the typical products by identifying and evaluating nutritional quality and safety characteristics represents an important goal for the preservation of local ecosystems [52,53].

We previously reported differences in some of the characteristics of four Italian landraces of white and red garlic: Rosso di Castelliri, Bianco Piacentino, Rosso di Sulmona, and Rosso di Proceno qualified on the national market, and some enrolled in the Italian Register of varieties, with regard to their carbohydrate profile [27]. These varieties were well characterized as regards their morphological and organoleptic properties, but not as regards their chemical-nutritional characteristics, which are substantially determined by the genotype, cultivation, techniques/agronomic practices, and environmental conditions.

In this context, this study has been conducted to determine the content of the main minerals, oligo-elements, and soluble vitamins and, primarily, to evaluate how cultivar and growing area may affect the amount of micronutrients for the four "typical varieties" produced with the same agronomic procedures in two different geographical areas of the Lazio region (Viterbo and Alvito).

\section{Materials and Methods}

\subsection{Samples}

Four traditional ecotypes of Allium sativum L. were chosen for this study: Bianco Piacentino, Rosso di Castelliri, Rosso di Sulmona, and Rosso di Proceno. All four varieties, named for their geographic origin, were widespread in Italy and grown in many geographic areas; the samples studied were produced in the Lazio region, in two different geographical areas (Viterbo and Alvito), using the same trail conditions (Table 1).

Table 1. Main agronomic trail of garlic production.

\begin{tabular}{|c|c|}
\hline \multicolumn{2}{|c|}{ Agronomic Trail } \\
\hline Basal dressing (kg/ha) & 250 (potassium sulphate) 250 (DAP 18/46) \\
\hline Top dressing $(\mathrm{kg} / \mathrm{ha})$ & $\begin{array}{c}\text { In the first decade of March } 150 \\
\text { (ammonium nitrate)- in the second decade } \\
\text { of April } 250 \text { (ammonium nitrate) }\end{array}$ \\
\hline $\begin{array}{l}\text { Fertilisation Unit for proposed } \\
\text { technique }\end{array}$ & $\begin{array}{c}143 \mathrm{~N} \\
115 \mathrm{P} \\
125 \mathrm{~K} \\
44 \mathrm{~S} \\
3 \mathrm{mg}\end{array}$ \\
\hline $\begin{array}{l}\text { Fertilisation Unit for conventional } \\
\text { technique }\end{array}$ & $\begin{array}{c}97 \mathrm{~N} \\
115 \mathrm{P} \\
44 \mathrm{~S}\end{array}$ \\
\hline Antiparasitic treatment (number) & 1 (melody compact -Iprovalicarb + oxychloride-) \\
\hline Antiparasitic inspection (number) & $\begin{array}{c}6 \text { (copper-based products -bordeaux mixture and } \\
\text { copper oxychloride- in spring) }\end{array}$ \\
\hline Pest check (L/ha) & $\begin{array}{l}\text { 3-Stomp-Pendimetalin based in pre-emergency } \\
1.5 \text {-Setossidim in post-emergency }\end{array}$ \\
\hline
\end{tabular}


The main chemical parameters of garlic soils coming from Alvito and Viterbo were reported in Table 2.

Table 2. Characteristics of Viterbo and Alvito soil.

\begin{tabular}{ccc}
\hline Parameter (Unit) & Viterbo & Alvito \\
\hline pH (1:2.5 in water) & 6.6 & 7.7 \\
\hline Total N (\% of soil d.w.) & 0.09 & 0.20 \\
\hline Assimilable P (ppm. Olsen's method) & 33 & 78 \\
\hline Exchangeable K (ppm. Intern's method) & 421 & 342 \\
\hline $\mathrm{CaCO}_{3}(\%$ of soil d.w.) & 5.1 & 11.2 \\
\hline Sand (\% of soil d.w.) & 65 & 6 \\
\hline Silt (\% of soil d.w.) & 23 & 48 \\
\hline Clay (\% of soil d.w.) & 12 & 46 \\
\hline
\end{tabular}

The four landraces of garlic selected can be distinguished thanks to some morphological characteristics, such as outer skin color of bulb, skin color of the cloves, and shape and structures of bulb. Furthermore, variability between cultivars was described for some biometric parameters, such as bulb size and the number of cloves for each bulb [27].

All four varieties were cultivated, harvested, and collected for the study between 15 June and 30 July of the same year.

For each ecotype, two pools (each made from 12 garlic) representing the two production areas were prepared; each pool was homogenized and analyzed for their moisture content, then prepared according to the different analyses: cut/ground/cool; cut/frozen; and cut/freeze-dried.

\subsection{Analytical Procedures}

\subsubsection{Quality Assurance}

The contents were found through single determinations and continuous monitoring of the quality of the analyses, including reference materials, duplicate determinations, and recoveries in the analytical series. Quality assurance showed that the quality of the analyses was satisfactory. Quality control of analytical procedures was performed through the precise and accurate execution of the validated methods. Appropriate reagents, equipment and suitable tests (e.g., System Suitability Testing) were used during the analysis to check the analytic repeatability and the validity of the result; the standard deviation (SD) of all the analytical values was calculated; and the accuracy of the procedure was established by the analysis of standard reference materials (SRMs) and standard compounds.

\subsubsection{Minerals and Oligo-Elements}

Mineral (Na, K, Ca, mg, P) and oligo-element (Fe, Cu, Zn, Mn) contents were determined by ICP-Plasma (OPTIMA 8000- Perkin-Elmer) after liquid ashing (6 mL $\left.\mathrm{HNO}_{3}+1 \mathrm{~mL} \mathrm{H}_{2} \mathrm{O}_{2}\right)$ of the samples in a microwave digestion system (MILESTONE, ETHOS ONE). The standard reference material: spinach (Nist 1570, National Institute of Standards and Technology, TA, U.S. Department of Commerce) was analyzed as a check of the accuracy of the analysis.

\subsubsection{Vitamins}

\section{- $\quad$ Sample preparation vitamin C}

The total vitamin $C$ was calculated using extraction of two separate rates of the same sample fresh, finely chopped and homogenized. The first aliquot of MPA was added (metaphosphoric acid) to 5\% for the extraction of AA (Ascorbic acid), while the second aliquot was added with DTT (Dithiothreitol) used as the reducing solution for the extraction of DHAA (dehydroascorbic acid) [54], filtered with a $0.45 \mu \mathrm{m}$ filter and injected. 


\section{- $\quad$ Sample preparation B vitamins}

Freeze-dried samples were hydrolyzed with $0.1 \mathrm{M} \mathrm{HCL}$ in an autoclave at $121^{\circ} \mathrm{C}$ for $30 \mathrm{~min}$, and after cooling the solution was adjusted to $\mathrm{pH} 4.5$ with soda and addition of $2 \mathrm{~mL}$ of a solution of enzyme taka diastase and b-amylase, for $17 \mathrm{~h}$ in thermostated bath at $37^{\circ} \mathrm{C}$. After cooling, the samples were diluted to a final volume of $25 \mathrm{~mL}$ with water, centrifuged for 15 min at 12,000 RPMA $2{ }^{\circ} \mathrm{C}$, filtered with 0.45 um filter and injected.

- Chromatographic determination

Content of vitamin C, measured as total ascorbic acid (TAA) and ascorbic acid (AA), was determined by HPLC Waters, equipped with a gradient pump 600, autosampler 717 plus, column Alltech (Alltima NH2, $5 \mu \mathrm{m}, 4.6 \times 250 \mathrm{mM}$ ), and UV detector, 996 photodiode array, at $248 \mathrm{~nm}$ [54]. The concentration of dehydroascorbic acid (DHAA) was calculated by subtraction method.

Riboflavin, Niacin, Thiamine and vitamins B6 were determined by the method of HPLC, using a column C-8 (Acclain 120, $5 \mu \mathrm{m}, 4.6 \times 250 \mathrm{mM}$ ), with a gradient mobile phase consisting of $50 \mathrm{mM}$ phosphate buffer at $\mathrm{pH}=2.5$ and methanol at a flow rate of $1.5 \mathrm{~mL} / \mathrm{min}$.

For the analysis, we used a chromatograph DIONEX (Sunyvale, CA, USA) equipped with a gradient pump GP50, an autosampler ASI-100, and a fluorescence detector RF2000, with wavelengths $\mathrm{Ex}=290, \mathrm{Em}=395$, and $\mathrm{EX}=422 \mathrm{Em}=522$, respectively, for the determination of piridoxamina, piridoxale, piridoxolo and riboflavin. Thiamine and niacin were determined with a detector UVD170S wavelengths $254 \mathrm{~nm}$ and $261 \mathrm{~nm}[55,56]$.

\subsection{Statistical Analysis}

All analyses were performed in triplicate. Data were expressed as means \pm standard deviation (SD). The statistical analysis was performed using SPSS Software Package 22.0 version (SPSS Inc., Chicago, IL, USA). Two-way ANOVA was done to determine the impact of area, cultivar and their interaction effect. Multiple comparisons of means were performed by applying the Tukey HSD test. The student's $t$-test was used to compare the cultivation areas for each cultivar. A $p$-value of less than 0.05 was taken as significant.

\section{Results and Discussion}

The content of essential minerals and oligo-elements in the four landraces of garlic were reported in Table 3. The data showed that potassium $(\mathrm{K})$ was the highest mineral detected, ranging from $645 \mathrm{mg} / 100 \mathrm{~g}$ d.w. of Bianco Piacentino produced in Alvito, to $1057 \mathrm{mg} / 100 \mathrm{~g}$ d.w. of Rosso di Sulmona grown in the same area. These values were comparable to those reported by Bonasia [53], but lower than those reported by Hacıseferoğulları, et al. [57], on a Turkish garlic variety $(21,378.84 \mathrm{mg} / \mathrm{Kg})$. The statistical analysis (Table 3) revealed that the cultivar, the geographical area, and the interaction between these variables affected the $\mathrm{K}$ content, probably reflecting the high exchangeable $\mathrm{K}$ value in Viterbo soil (Table 2).

On the other hand, the lowest phosphorus $(\mathrm{P})$ concentration was found in Bianco Piacentino bulbs produced in Alvito (219 mg/100 g d.w.), whilst the Rosso di Castelliri garlic grown in Viterbo (347 mg/100 g d.w.) showed the highest content. These values were higher than those found by Abayomi et al. [58] in garlic from Nigeria that showed a P content of about $10.19 \mathrm{mg} / \mathrm{g}$ d.w. As reported in Table 3, the P content was influenced by the growing area, cultivar and by the interaction between the two variables, suggesting that the pedoclimatic characteristics, together with the genetic ones, contribute to determine the quantity of this mineral in bulbs. The amounts of $P$ in samples can be related to the technical and agronomic trail of garlic (Table 1). In this regard, some authors $[49,50,59,60]$ indicated that fertilization of garlic plant with inorganic N, P and S significantly increased the $\mathrm{N}, \mathrm{P}, \mathrm{K}$ and $\mathrm{S}$ concentration in garlic bulb tissues $[46,48]$.

Magnesium $(\mathrm{Mg}$ ) content varied between $37 \mathrm{mg} / 100 \mathrm{~g}$ d.w. (Bianco Piacentino from Alvito) and $54 \mathrm{mg} / 100 \mathrm{~g}$ d.w. (Rosso di Castelliri from Viterbo). As shown in Table 3, the mg 
content was influenced by both the cultivar and the soils of growth. The Student's test carried out to compare the two cultivation areas of each ecotype only showed significant differences for the Bianco Piacentino.

Table 3. Levels of minerals and oligo-elements (mg/100 g d.w.) in four garlic landraces from the Viterbo and Alvito areas.

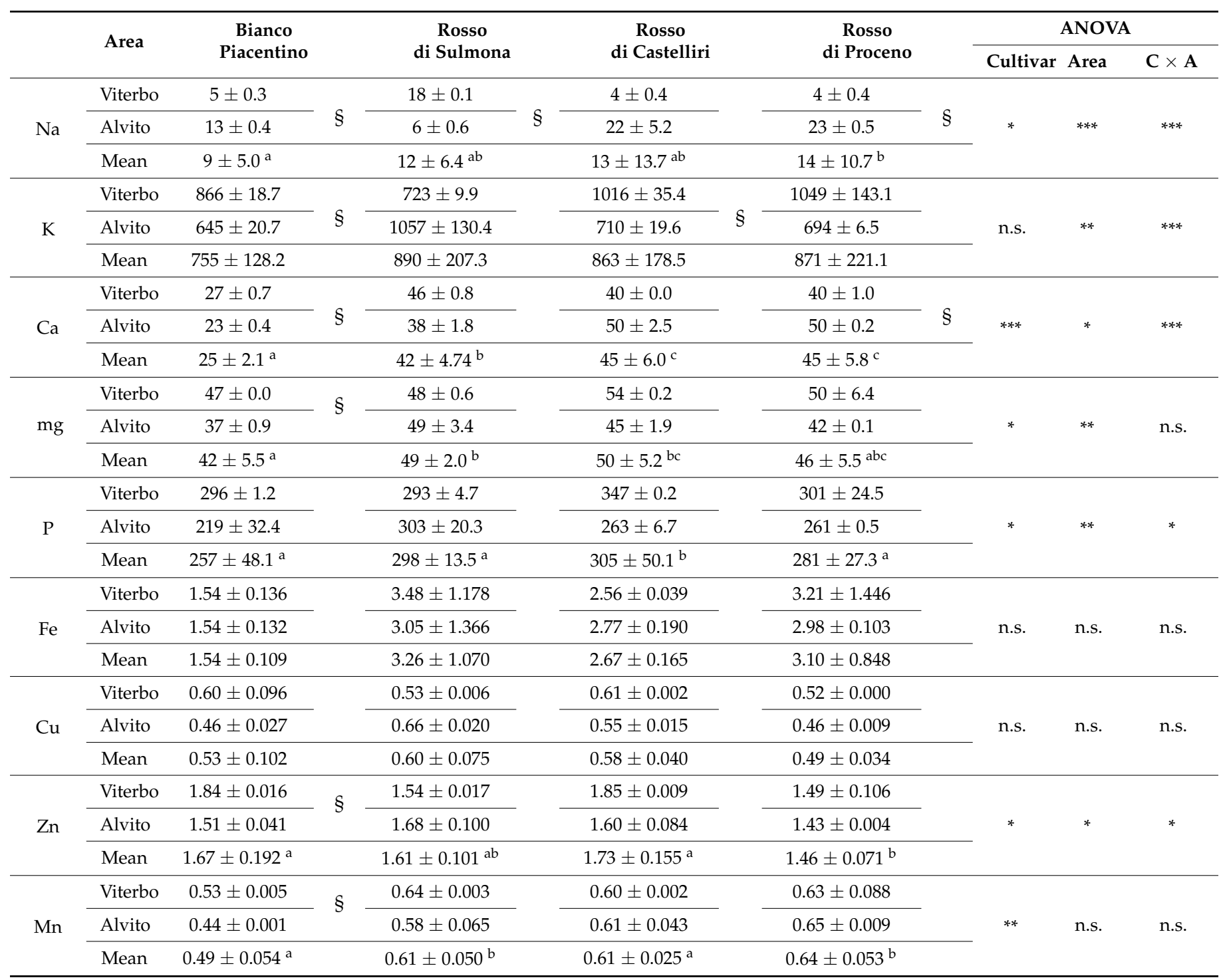

Data are expressed as Mean \pm S.D.; Student's $t$-test between two areas of each cultivar: $\S$ is statistically significant $(p<0.05)$. Two-way ANOVA effect: * statistically significant differences at $p$ below 0.05 ; ** statistically significant differences at $p$-value below 0.01 ; ${ }^{* * *}$ statistically significant differences at $p$-value below 0.001 . Tukey's honestly significant difference (HSD) test: by row, means of each cultivar followed by different superscript $(\mathrm{a}, \mathrm{b}, \mathrm{c})$ are significantly different $(p<0.05)$.

With regards to $(\mathrm{Ca})$, the lowest amounts were found in the Bianco Piacentino landrace; with values of $23 \mathrm{mg} / 100 \mathrm{~g}$ d.w. and $27 \mathrm{mg} / 100 \mathrm{~g}$ d.w. (cultivated in Viterbo and Alvito, respectively), in agreement with the values detected by Brandolini et al. [61]. On the contrary, the highest Ca values were detected in Rosso di Castelliri and Rosso di Proceno (50 mg/100 g d.w.), both from Alvito. The Ca levels in the four landraces were in line with those reported by Bonasia [53], where six Italian ecotypes of garlic from Puglia region were analyzed. As reported in Table 3, the amount of Ca in bulbs were strongly affected by cultivar; however, it was also influenced by both the soil and from the interaction of the two variables. The Tukey's test performed to compare the groups showed that there were not significant differences in the Ca content of Rosso di Castelliri and the Rosso di Proceno cultivars. On the contrary, the Ca in Bianco Piacentino presented significant differences if compared to the other three ecotypes, as did Rosso di Sulmona (Table 3). 
Statistical analysis conducted for determining the effect of the soil for each landrace showed significant differences between Alvito and Viterbo areas for the Bianco Piacentino and Rosso di Proceno varieties.

As for sodium $(\mathrm{Na})$, the results showed heterogeneous values, ranging from $4 \mathrm{mg} / 100 \mathrm{~g}$ d.w. in Rosso di Castelliri and Rosso di Proceno, both cultivated in Viterbo, to $23 \mathrm{mg} / 100 \mathrm{~g}$ d.w. in Rosso di Proceno grown in Alvito. A two-way ANOVA test demonstrated that Na can be influenced by the growing area, as well as by the genotype and also by the interaction between the two variables (Table 3). Differences between the geographic regions were evident and significant for three cultivars (Rosso di Sulmona, Bianco Piacentino, Rosso di Proceno). The Na values studied on fresh samples (data not shown) ranged from $2 \mathrm{mg} 100 \mathrm{~g}$ f.w. of Rosso di Castelliri grown in Viterbo, to $9 \mathrm{mg} / 100 \mathrm{~g} \mathrm{f.w}$. of Rosso di Proceno cultivated in Alvito, in accordance to the mean value of $4 \mathrm{mg} / 100 \mathrm{~g}$ f.w., observed for Italian commercial garlic present in CREA'S Food Composition Tables [62]. A similar heterogeneity in the sodium content was also reported by Petropoulos at al. [41], although they reported higher values ranging from $7.0 \mathrm{mg} / 100 \mathrm{~g}$ f.w. to $36 \mathrm{mg} / 100 \mathrm{f} . \mathrm{w}$. were reported.

Among the oligo-elements, iron $(\mathrm{Fe})$ was the most representative in garlic bulbs, and this content ranged between $1.54 \mathrm{mg} / 100 \mathrm{~g}$ d.w. of the Bianco Piacentino from Alvito and Viterbo, to $3.48 \mathrm{mg} / 100 \mathrm{~d} . \mathrm{w}$. of Rosso di Sulmona produced in Viterbo. The value of the Fe did not depend on the characteristics of the cultivar and the cultivation soil, as demonstrated by statistical analysis (Table 3).

The quantity of zinc $(\mathrm{Zn})$ was rather homogeneous in all samples and ranged from $1.43 \mathrm{mg} / 100 \mathrm{~g} \mathrm{~d} . \mathrm{w}$. detected in Rosso di Proceno from Alvito to $1.85 \mathrm{mg} / 100 \mathrm{~g} \mathrm{~d}$.w. of Rosso Castelliri from Viterbo; despite this, the statistical analysis showed that the $\mathrm{Zn}$ content was influenced by soil, cultivar and the interaction between these (Table 3). $\mathrm{Zn}$ concentrations were similar to those reported by Islam et al. [63] for large multi-clove garlics from India, China and Bangladesh, where $\mathrm{Zn}$ content was in the range of from 9.6 ppm and to $19.18 \mathrm{ppm}$.

Concerning the copper $(\mathrm{Cu})$ content, the concentrations were found between $0.46 \mathrm{mg} / 100 \mathrm{~g} \mathrm{d.w}$. of Bianco Piacentino and Rosso di Proceno (both from Alvito) and $0.66 \mathrm{mg} / 100 \mathrm{~g}$ d.w. of Rosso di Sulmona grown in Alvito (Table 3). These quantities were not affected by any of the variables considered.

The detection of manganese (Mn) showed that this oligo-element was in a smallest amount, $0.44 \mathrm{mg} / 100 \mathrm{~g}$ d.w., in Bianco Piacentino cultivar grown in Alvito, and as a maximum value of $0.65 \mathrm{mg} / 100 \mathrm{~g}$ d.w. in Rosso di Proceno grown in Alvito. These data were higher than the values reported by Abayomi [58] and Otunola [64]. The values of the Mn were influenced only by the types of the cultivar (Table 3).

The contents of vitamin B6 in the different cultivars (Table 4) were rather heterogeneous with the lowest value of $0.88 \mathrm{mg} / 100 \mathrm{~g}$ f.w. found in the Rosso di Proceno grown in Alvito and with the highest one of $2.04 \mathrm{mg} / 100 \mathrm{~g}$ f.w. recorded in the Rosso di Castelliri from Viterbo. These data were higher than the value of $0.32 \mathrm{mg} / 100 \mathrm{~g}$ f.w. published by Cardelle-Cobas [65]. Vitamin B6 in the four garlic landraces were influenced by the characteristics of cultivar, soil and interaction between these (Table 4).

Niacin concentrations were included between $0.56 \mathrm{mg} / 100 \mathrm{~g}$ f.w. of Rosso di Proceno grown in Alvito, and $0.9 \mathrm{mg} / 100 \mathrm{~g}$ f.w. of Bianco Piacentino grown in the Viterbo region and Rosso di Sulmona grown in Alvito. Values obtained were comparable with those reported on the Standard Tables of Food Composition in Japan, which shows a Niacin amount corresponding to $0.7 \mathrm{mg} / 100 \mathrm{~g}$ f.w. [66]. Statistical analysis confirmed that the concentration of this vitamin was influenced only by the cultivar, but not by growth area, as confirmed by the Student's $t$-test for the comparison of means of the two areas.

Table 4 shows the content of some water-soluble vitamins in the studied samples. The values pointed out that, among the B-group vitamins, vitamin B6 was the most represented, followed by niacin, thiamine and finally riboflavin. Vitamin $\mathrm{C}$ was contained in greater quantities than all other vitamins detected. 
Table 4. Levels of vitamins (mg/100 g f.w.) in four garlic landraces from the Viterbo and Alvito areas.

\begin{tabular}{|c|c|c|c|c|c|c|c|c|c|c|}
\hline & \multirow{2}{*}{ Area } & \multirow{2}{*}{$\begin{array}{c}\text { Bianco } \\
\text { Piacentino }\end{array}$} & \multirow{2}{*}{$\begin{array}{c}\text { Rosso } \\
\text { di Sulmona }\end{array}$} & \multirow{2}{*}{\multicolumn{2}{|c|}{$\begin{array}{c}\text { Rosso } \\
\text { di Castelliri }\end{array}$}} & & \multirow{2}{*}{$\begin{array}{c}\text { Rosso } \\
\text { di Proceno }\end{array}$} & \multicolumn{3}{|c|}{ ANOVA } \\
\hline & & & & & & & & Cultivar & Area & $\mathrm{C} \times \mathrm{A}$ \\
\hline \multirow{3}{*}{ Thiamine } & Viterbo & $0.27 \pm 0.077$ & $0.20 \pm 0.005$ & & $0.26 \pm 0.005$ & & $0.21 \pm 0.036$ & \multirow{3}{*}{ n.s. } & \multirow{3}{*}{ n.s. } & \multirow{3}{*}{ n.s. } \\
\hline & Alvito & $0.25 \pm 0.073$ & $0.19 \pm 0.017$ & & $0.22 \pm 0.020$ & & $0.24 \pm 0.010$ & & & \\
\hline & Mean & $0.26 \pm 0.062$ & $0.19 \pm 0.011$ & & $0.24 \pm 0.025$ & & $0.22 \pm 0.025$ & & & \\
\hline \multirow{3}{*}{ Riboflavin } & Viterbo & $0.02 \pm 0.001$ & $0.01 \pm 0.001$ & & $0.04 \pm 0.002$ & & $0.02 \pm 0.001$ & \multirow{3}{*}{$* * *$} & \multirow{3}{*}{ * } & \multirow{3}{*}{$* * *$} \\
\hline & Alvito & $0.02 \pm 0.002$ & $0.02 \pm 0.000$ & $\S-$ & $0.02 \pm 0.002$ & $\S$ & $0.02 \pm 0.001$ & & & \\
\hline & Mean & $0.02 \pm 0.002^{a}$ & $0.02 \pm 0.004^{a}$ & & $0.03 \pm 0.011^{b}$ & & $0.02 \pm 0.001^{a}$ & & & \\
\hline \multirow{3}{*}{ Niacin } & Viterbo & $0.91 \pm 0.000$ & $0.80 \pm 0.060$ & & $0.66 \pm 0.040$ & & $0.62 \pm 0.020$ & \multirow{3}{*}{$* * *$} & \multirow{3}{*}{ n.s } & \multirow{3}{*}{ n.s } \\
\hline & Alvito & $0.77 \pm 0.030$ & $0.91 \pm 0.030$ & & $0.60 \pm 0.040$ & & $0.56 \pm 0.030$ & & & \\
\hline & Mean & $0.84 \pm 0.084^{a}$ & $0.86 \pm 0.075^{a}$ & & $0.63 \pm 0.047^{b}$ & & $0.59 \pm 0.039^{b}$ & & & \\
\hline \multirow{3}{*}{ Vitamin B6 } & Viterbo & $1.60 \pm 0.010$ & $1.37 \pm 0.090$ & & $2.04 \pm 0.230$ & \multirow[b]{2}{*}{$\S$} & $1.03 \pm 0.052$ & \multirow{3}{*}{$* * *$} & \multirow{3}{*}{ n.s. } & \multirow{3}{*}{ n.s. } \\
\hline & Alvito & $0.98 \pm 0.097$ & $1.37 \pm 0.026$ & & $0.99 \pm 0.056$ & & $0.88 \pm 0.072$ & & & \\
\hline & Mean & $1.29 \pm 0.357^{\mathrm{a}}$ & $1.37 \pm 0.054^{\mathrm{a}}$ & & $1.52 \pm 0.609^{b}$ & & $0.96 \pm 0.099^{c}$ & & & \\
\hline \multirow{3}{*}{ Vitamin C } & Viterbo & $11.4 \pm 2.23$ & $12.6 \pm 3.61$ & & $13.0 \pm 3.97$ & & $9.7 \pm 1.85$ & \multirow{3}{*}{ n.s. } & \multirow{3}{*}{ n.s. } & \multirow{3}{*}{ n.s. } \\
\hline & Alvito & $12.4 \pm 2.93$ & $15.6 \pm 8.48$ & & $14.6 \pm 6.16$ & & $10.5 \pm 6.03$ & & & \\
\hline & Mean & $11.9 \pm 2.21$ & $14.1 \pm 5.60$ & & $13.8 \pm 4.32$ & & $10.1 \pm 3.66$ & & & \\
\hline
\end{tabular}

Data are expressed as Mean \pm S.D.; Student's $t$-test between two areas of each cultivar: $\S$ is statistically significant $(p<0.05)$. Two-way ANOVA effect: * statistically significant differences at $p$ below $0.05 ; * * *$ statistically significant differences at $p$-value below 0.001 . Tukey's honestly significant difference (HSD) test: by row, means of each cultivar followed by different superscript $(\mathrm{a}, \mathrm{b}, \mathrm{c})$ are significantly different $(p<0.05)$.

As reported in Table 4, the lowest thiamine content was found in the Rosso di Sulmona from Alvito (0.19 mg/100 g f.w.); whereas the highest content was that of Bianco Piacentino grown in Viterbo $(0.27 \mathrm{mg} / 100 \mathrm{~g}$ f.w.). The obtained values were comparable with those reported on the Italian Food Composition Tables [62], where thiamine value for commercial samples of garlic is $0.23 \mathrm{mg} / 100 \mathrm{~g}$ f.w. The thiamine content was not influenced by the cultivation area, nor by the cultivar, nor by the interaction of the two variables considered. Statistical analysis comparing the means between areas of each cultivar confirmed that there were no significant differences for any pair of samples studied.

The lowest content of riboflavin was detected in the Rosso di Sulmona from Viterbo with a value of $0.01 \mathrm{mg} / 100 \mathrm{~g}$ f.w, while the highest content was that of Rosso Castelliri from Viterbo (0.04 mg/100 g f.w.). All values were lower than those reported for samples in the Italian Food Composition Tables [62] corresponding to $0.07 \mathrm{mg} / 100 \mathrm{~g}$. Furthermore, the ANOVA test showed that the riboflavin concentration was influenced by the growth area, the cultivar and by the interaction between these two factors (Table 4). Differences between the cultivation areas for each cultivar were significant for Rosso di Sulmona and Rosso Castelliri.

Vitamin C content ranged from a minimum value of $9.7 \mathrm{mg} / 100 \mathrm{~g}$ found in Rosso di Proceno coming from Viterbo, to a maximum value corresponding to $15.6 \mathrm{mg} / 100 \mathrm{~g}$ in Rosso di Sulmona grown in Alvito. These amounts were comparable to those reported on the Standard Tables of Food Composition in Japan, which reports a Vitamin C value of $12 \mathrm{mg} / 100 \mathrm{~g}$ f.w. [66]. Conversely, the values obtained were distinctively higher than those reported for some Italian varieties by Fratianni et al. [67] and were not significantly influenced by soil, cultivar or cultivar-soil interaction (Table 4). These results may be due to the fact that the vitamin $C$ content depends on many factors, not least its sensitivity to pre- and post-harvest conditions [68]. It is well known that different crop varieties produce and store different amounts of vitamin $C$ in their tissues, and its concentration is affected by a combination of factors, such as the cultivar type, climatic and soil conditions, 
maturity at harvest, storage duration and conditions, type and duration of chemical and thermal processing, physical damage, etc. [69].

\section{Conclusions}

Our results indicated that the four Italian garlic landraces studied were a good source of minerals and vitamins, and their content was differently affected by the genotype and the growing area. The most represented mineral was $\mathrm{K}$, followed by $\mathrm{P}, \mathrm{mg}$ and $\mathrm{Ca}$. These concentrations were influenced by the cultivation area and therefore by the characteristics of the soil, since the agronomic trails were the same for Viterbo and Alvito areas.

As concerns the vitamins, the results showed that vitamin $C$ was the most represented, and its values were independent from the area and cultivar.

The values of the $B$ vitamins showed a greater cultivar effect for riboflavin, niacin and vitamin B6. Furthermore, many of the micronutrients were influenced by the interaction between cultivar and growing area, suggesting that the effect of the soil on their content is expressed in the presence of some characteristics related to the genotype.

Therefore, the study of the chemical composition of traditional foodstuffs and their nutritional characteristics, in relation to biodiversity, is important for the definition of their total quality and to enhances and preserves the identity of local products. Furthermore, knowledge about the properties of these garlic varieties could also promote their cultivation and consumption as food. Nowadays, garlic is used mainly in the formulation of food supplements, for its beneficial effects on blood pressure and on the functionality of the cardiovascular system.

Author Contributions: Conceptualization, S.L., L.G., S.M. and L.M.; methodology, L.G., A.A., P.G., S.L. and S.M.; software, E.C.; validation, L.M., A.D., L.G. and S.L.; investigation, A.D., L.M., A.A., P.G.; data curation, S.M., S.L., E.C. and L.G.; writing-original draft preparation, S.M. and E.C.; writing - review and editing, A.D.; supervision, S.L., L.M. and S.M. All authors have read and agreed to the published version of the manuscript.

Funding: This research received no external funding.

Acknowledgments: This research was supported by the Ministry of Agricultural, Food and Forestry Policies-BIOVITA Project.

Conflicts of Interest: The authors declare no conflict of interest.

\section{References}

1. Yang, X.F.; Zhang, Y. Myanmar Typical Vegetables; University of Science and Technology of China Press: Hefei, China, 2018.

2. Wallace, T.C.; Bailey, R.L.; Blumberg, J.B.; Burton-Freeman, B.; Chen, C.O.; Crowe-White, K.M.; Drewnowski, A.; Hooshmand, S.; Johnson, E.; Lewis, R.; et al. Fruits, vegetables, and health: A comprehensive narrative, umbrella review of the science and recommendations for enhanced public policy to improve intake. Crit. Rev. Food Sci. Nutr. 2020, 60, 2174-2211. [CrossRef]

3. Maggini, S.; Maldonado, P.; Cardim, P.; Fernandez Newball, C.; Sota Latino, E.R. Vitamins C, D and Zinc: Synergistic Roles in Immune Function and Infections. Vitam Min. 2017, 6, 1318-2376. [CrossRef]

4. Moreb, N.A.; Albandary, A.; Jaiswal, S.; Jaiswal, A.K. Fruits and Vegetables in the Management of Underlying Conditions for COVID-19 High-Risk Groups. Foods 2021, 10, 389. [CrossRef]

5. Berg, J.M.; Tymoczko, J.L.; Stryer, L. Biochemistry, 5th ed.; Section 8.6, Vitamins are often Precursors to Coenzymes; W. H. Freeman: New York, NY, USA, 2002. Available online: https://www.ncbi.nlm.nih.gov/books/NBK22549/ (accessed on 5 April 2021).

6. Deakin, V. Micronutrients. In Sport and Exercise Nutrition, 1st ed.; Lanham-New, S.A., Stear, S.J., Shirreffs, S.M., Collins, A.L., Eds.; Wiley-Blackwel: Oxford, UK, 2011; pp. 68-99.

7. Tardy, A.-L.; Pouteau, E.; Marquez, D.; Yilmaz, C.; Scholey, A. Vitamins and Minerals for Energy, Fatigue and Cognition: A Narrative Review of the Biochemical and Clinical Evidence. Nutrients 2020, 12, 228. [CrossRef] [PubMed]

8. Gharibzahedi, S.M.T.; Jafari, S.M. The importance of minerals in human nutrition: Bioavailability, food fortification, processing effects and nanoencapsulation. Trend. Food Sci. Technol. 2017, 62, 119-132. [CrossRef]

9. Watson, J.; Lee, M.; Garcia-Casal, M.N. Consequences of Inadequate Intakes of Vitamin A, Vitamin B12, Vitamin D, Calcium, Iron, and Folate in Older Persons. Curr. Geriatr. Rep. 2018, 7, 103-113. [CrossRef] [PubMed]

10. Castiglione, D.; Platania, A.; Conti, A.; Falla, M.; D’Urso, M.; Marranzano, M. Dietary Micronutrient and Mineral Intake in the Mediterranean Healthy Eating, Ageing, and Lifestyle (MEAL) Study. Antioxidants 2018, 7, 79. [CrossRef] [PubMed] 
11. Asensi-Fabado, M.A.; Munne-Bosch, S. Vitamins in plants: Occurrence, biosynthesis and antioxidant function. Trends Plant Sci. 2010, 15, 582-592. [CrossRef] [PubMed]

12. Yang, C.S.; Ho, C.T.; Zhang, J.; Wan, X.; Zhang, K.; Lim, J. Antioxidants: Differing meanings in food science and health science. J. Agric. Food Chem. 2018, 66, 3063-3068. [CrossRef]

13. Lykstad, J.; Sharma, S. Biochemistry, Water Soluble Vitamins. 12 April 2020. In StatPearls [Internet]; StatPearls Publishing: Treasure Island, FL, USA, 2021. Available online: https:/ / www.ncbi.nlm.nih.gov/books/NBK538510/ (accessed on 21 September 2020).

14. Reddy, P.; Jialal, I. Biochemistry, Fat Soluble Vitamins. In StatPearls [Internet]; StatPearls Publishing: Treasure Island, FL, USA, 2021. Available online: https://www.ncbi.nlm.nih.gov/books/NBK534869/ (accessed on 21 September 2020).

15. White, P.J.; Broadley, M.R. Biofortification of crops with seven mineral elements often lacking human diets-iron, zinc, copper, calcium, magnesium, selenium and iodine. New Phytol. 2009, 182, 49-84. [CrossRef]

16. Anuraj, H.S. 140-Mineral Deficiencies. In Hunter's Tropical Medicine and Emerging Infectious Disease, 9th ed.; Magill, A.J., Hill, D.R., Solomon, T., Ryan, E.T., Eds.; W.B. Saunders: Philadelphia, PA, USA, 2013; pp. 1003-1010.

17. Giammarioli, S.; Boniglia, C.; Carratù, B.; Ciarrocchi, M.; Chiarotti, F.; Mosca, M.; Sanzini, E. Use of food supplements and determinants of usage in a sample Italian adult population. Public Health Nutr. 2013, 16, 1768-1781. [CrossRef]

18. Ruel, M.T.; Alderman, H. Maternal and Child Nutrition Study Group. Nutrition-sensitive interventions and programmes: How can they help to accelerate progress in improving maternal and child nutrition? Lancet 2013, 382, 536-551. [CrossRef]

19. Peñafiel Anchundia, D.D.; Cevallos-Valdiviezo, H.; Espinel, R.; Van Damme, P. Local traditional foods contribute to diversity and species richness of rural women's diet in Ecuador. Public Health Nutr. 2019, 22, 2962-2971. [CrossRef]

20. Block, E. Garlic and Other Alliums: The Lore and the Science; Royal Society of Chemistry, RSC Publishing: Cambridge, UK, 2010; p. 759.

21. Amagase, H.; Petesch, B.L. Garlic. Encyclopedia of Food Sciences and Nutrition, 2nd ed.; Caballero, B., Ed.; Academic Press: London, UK, 2003; pp. 2861-2864. ISBN 9780122270550.

22. Petrovska, B.B.; Cekovska, S. Extracts from the history and medical properties of garlic. Pharmacogn. Rev. 2010, 4, 106-110. [CrossRef] [PubMed]

23. Rivlin, R.S. Historical perspective on the use of garlic. J. Nutr. 2001, 131, 951S-954S. [CrossRef]

24. Charu, K.; Yogita, S.; Sonali, S. Neutraceutical potential of organosulfur compounds in fresh garlic and garlic preparations. Int. J. Pharm. Bio. Sci. 2014, 5, 978-982.

25. Botas, J.; Fernandes, Â.; Barros, L.; Alves, M.J.; Carvalho, A.M.; Ferreira, I.C.F.R. A Comparative Study of Black and White Allium sativum L.: Nutritional Composition and Bioactive Properties. Molecules 2019, 24, 2194. [CrossRef]

26. Durazzo, A. Study Approach of Antioxidant Properties in Foods: Update and Considerations. Foods 2017, 6, 17. [CrossRef] [PubMed]

27. Lisciani, S.; Gambelli, L.; Durazzo, A.; Marconi, S.; Camilli, E.; Rossetti, C.; Gabrielli, P.; Aguzzi, A.; Temperini, O.; Marletta, L. Carbohydrates Components of Some Italian Local Landraces: Garlic (Allium sativum L.). Sustainability 2017, 9, 1922. [CrossRef]

28. Patumraj, S.; Tewit, S.; Amatyakul, S.; Jariyapongskul, A.; Maneesri, S.; Kasantikul, V.; Shepro, D. Comparative Effects of Garlicand Aspirin on Diabetic Cardiovascular Complications. Drug Deliv. 2000, 7, 91-96.

29. Zeng, T.; Guo, F.F.; Zhang, C.L.; Song, F.Y.; Zhao, X.L.; Xie, K.Q. A meta-analysis of randomized, double-blind, placebo-controlled trials for the effects of garlic on serum lipid profiles. J. Sci. Food Agric. 2012, 92, 1892-1902. [CrossRef]

30. Raman, P.; Dewitt, D.L.; Nair, M.G. Lipid peroxidation and cyclooxygenase enzyme inhibitory activities of acidic aqueous extracts of some dietary supplements. Phytother. Res. PTR 2008, 22, 204-212. [CrossRef]

31. Zhang, Y.; Liu, X.; Ruan, J.; Zhuang, X.; Zhang, X.; Li, Z. Phytochemicals of garlic: Promising candidates for cancer therapy. Biomed. Pharm. 2020, 123, 109730. [CrossRef] [PubMed]

32. Devi, A.; Chaurasia, H.; Chandel, S.R.; Kaushik, S.; Bhatt, B. A Review: Impact of garlic on human health. Int. J. Pharm. Biol. Sci. 2021, 10, 935-947. [CrossRef]

33. Põldma, P.; Moor, U.; Tõnutare, T.; Herodes, K.; Rebane, R. Selenium treatment under field conditions affects mineral nutrition, yield and antioxidant properties of bulb onion (Allium cepa L.). Acta Sci. Pol. Hortorum Cultus 2013, 12, 167-181.

34. Martins, N.; Petropoulos, S.; Ferreira, I.C. Chemical composition and bioactive compounds of garlic (Allium sativum L.) as affected by pre- and post-harvest conditions: A review. Food Chem. 2016, 211, 41-50. [CrossRef]

35. Tocmo, R.; Liang, D.; Lin, Y.; Huang, D. Chemical and biochemical mechanisms underlying the cardioprotective roles of dietary organopolysulfides. Front. Nutr. 2015, 2, 1. [CrossRef] [PubMed]

36. Prianshu, A.; Singh, M.; Kumar, M.; Malik, S.; Sahahi, U.; Lodhi, S. Effect of integrated nutrient management on yield and quality of Garlic cv. Yamuna Safed-3. J. AgriSearch 2020, 7, 251-254.

37. Evrendilek, G.A. Nutritional Composition and Antioxidant Properties of Fruits and Vegetables; Jaiswal, A., Ed.; Academic Press: London, UK, 2020; pp. 89-105.

38. González, R.E.; Soto, V.C.; Sance, M.M.; Camargo, A.B.; Galmarini, C.R. Variability of solids, organosulfur compounds, pungency and health-enhancing traits in garlic (Allium sativum L.) cultivars belonging to different ecophysiological groups. J. Agric. Food Chem. 2009, 57, 10282-10288. [CrossRef] [PubMed]

39. Figliuolo, G.; Candido, V.; Logozzo, G.; Miccolis, V.; Zeuli, P.L.S. Genetic evaluation of cultivated garlic germplasm (Allium sativum L. and A. ampeloprasum L.). Euphytica 2001, 121, 325-334. [CrossRef] 
40. Mohammadi, B.; Khodadadi, M.; Karami, E.; Shaaf, S. Variation in agro-morphological characters in Iranian garlic landraces. Int. J. Veg. Sci. 2014, 20, 202-215. [CrossRef]

41. Petropoulos, S.; Fernandes, Â.; Ntatsi, G.; Petrotos, K.; Barros, L.; Ferreira, I.C.F.R. Nutritional Value, Chemical Characterization and Bulb Morphology of Greek Garlic Landraces. Molecules 2018, 23, 319. [CrossRef] [PubMed]

42. Kibar, B.; Temel, S. Evaluation of mineral composition of some wild edible plants growing in the Eastern Anatolia region grasslands of Turkey and consumed as vegetable. J. Food Process. Preserv. 2016, 1, 56-66. [CrossRef]

43. Atif, M.J.; Amin, B.; Ghani, M.I.; Hayat, S.; Ali, M.; Zhang, Y.; Cheng, Z. Influence of Different Photoperiod and Temperature Regimes on Growth and Bulb Quality of Garlic (Allium sativum L.) Cultivars. Agronomy 2019, 9, 879. [CrossRef]

44. Atif, M.J.; Amin, B.; Ghani, M.I.; Ali, M.; Cheng, Z. Variation in Morphological and Quality Parameters in Garlic (Allium sativum L.) Bulb Influenced by Different Photoperiod, Temperature, Sowing and Harvesting Time. Plants 2020, 9, 155. [CrossRef]

45. Smith, R. Determination of the country of origin of garlic (Allium sativum) using trace metal profiling. J. Agric. Food Chem. 2005, 53, 4041-4045. [CrossRef]

46. Diriba-Shiferaw, G. Review of Management Strategies of Constraints in Garlic (Allium sativum L.) Production. J. Agric. Sci. 2016, 11, 186-207. [CrossRef]

47. Naruka, I.S.; Dhaka, R.S. Effect of row spacing and nitrogen fertilization on growth, yield and composition of bulb in garlic (Allium sativum L.) cultivars. J. Spices Aromat. Crop. 2001, 10, 111-117.

48. Panda, S.C.; Panda, P.C.P.; Nanda, S.S. Nitrogen and phosphorus uptake from Tithonia diversifolia and inorganic fertilizers and their effect on maize yield in Malawi. In Proceedings of the Symposium on Maize Production Technology for the Future: Challenge and Opportunities, Addis Ababa, Ethiopia, 21-25 September 1998; pp. 264-266.

49. Surendra, S. Effect of sulphur on yields and S uptake by onion and garlic grown in acid alfisol of Ranchi. Agric. Sci. Digest. 2008, $28,189-191$.

50. Diriba-Shiferaw, G.; Nigussie-Dechassa, R.; Kebede, W.; Getachew, T.; Sharma, J.J. Growth and nutrients content and uptake of garlic (Allium sativum L.) as influenced by different types of fertilizers and soils. Sci. Technol. Arts Res. J. 2013, 2, 35-50. [CrossRef]

51. Shedeed, S.I.; El-Sayed, S.A.A.; Bash, D.A. Effectiveness of bio-fertilizers with organic matter on the growth, yield and nutrient content of onion (Allium cepa L.) plants. Eur. Inter. J. Sci. Tech. 2014, 3, 115-122.

52. Durazzo, A. The Close Linkage between Nutrition and Environment through Biodiversity and Sustainability: Local Foods, Traditional Recipes, and Sustainable Diets. Sustainability 2019, 11, 2876. [CrossRef]

53. Bonasia, A.; Conversa, G.; Lazzizera, C.; Loizzo, P.; Gambacorta, G.; Elia, A. Evaluation of Garlic Landraces from Foggia Province (Puglia Region; Italy). Foods 2020, 9, 850. [CrossRef]

54. Valls, F.; Rancho, M.T.; Fernandez-Muino, M.; Alonso-Torre, S.; Checa, A.M.A. High pressure liquid chromatography determination of ascorbic acid in cooked sausages. J. Food Prot. 2002, 65, 1771-1774. [CrossRef]

55. Arella, F.; Lahély, S.; Bourguignon, J.B.; Hasselmann, C. Liquid chromatographic determination of vitamins B1 and B2 in foods. A collaborative study. Food Chem. 1996, 56, 81-86. [CrossRef]

56. Gambelli, L.; Marconi, S. Messa a punto di una metodica HPLC per l'analisi contemporanea di alcune vitamine idrosolubili del gruppo B. In Proceedings of the VIII Congresso Nazionale di Chimica degli Alimenti, Marsala, Italy, 20-24 September 2010; pp. 496-499.

57. Hacıseferoğulları, H.; Özcan, M.; Demir, F.; Çalışır, S. Some nutritional and technological properties of garlic (Allium sativum L.). J. Food Eng. 2005, 68, 463-469. [CrossRef]

58. Yusuf, A.; Fagbuaro, S.S.; Fajemilehin, S.O.K. Chemical composition, phytochemical and mineral profile of garlic (Allium sativum). J. Biosci. Biotechnol. Discov. 2018, 3, 105-109. [CrossRef]

59. Bloem, E.; Haneklaus, S.; Schnug, E. Storage Life of Field-Grown Garlic Bulbs (Allium sativum L.) as Influenced by Nitrogen and Sulfur Fertilization. J. Agric. Food Chem. 2011, 59, 4442-4447. [CrossRef]

60. Diriba-Shiferaw, G.; Nigussie-Dechassa, R.; Woldetsadik, K.; Tabor, G.; Sharma, J.J. Bulb quality of Garlic (Allium sativum L.) as influenced by the application of inorganic fertilizers. Afr. J. Agric. Res. 2014, 9, 778-790. [CrossRef]

61. Brandolini, V.; Tedeschi, P.; Cereti, E.; Maietti, A.; Barile, D.; Coisson, J.; Mazzota, D.; Alrorio, M.; Martelli, A. Chemical and genomic combined approach applied to the characterization and identification of Italian Allium sativum L. J. Agric. Food Chem. 2005, 53, 678-683. [CrossRef]

62. Marletta, L.; Camilli, E. Aggiornamento 2019. Tabelle di Composizione Degli Alimenti. Available online: https://www. alimentinutrizione.it/sezioni/tabelle-nutrizionali (accessed on 28 April 2021).

63. Islam, D.; Lina, N.N.; Roy, R.K.; Lyzu, C.; Ahamed, Z.; Akhter, S.; Mohanta, L.C.; Lipy, E.P.; Hakim, M.; Roy, D.C. Relative Proximate Composition and Mineral Analysis of Three Garlic Varieties Available in Bangladesh. Eur. J. Med. Plants 2020, 1-9. [CrossRef]

64. Otunola, G.A.; Oloyede, O.B.; Oladiji, A.T.; Afolayan, A.J. Comparative analysis of the chemical composition of three spicesAllium sativum L. Zingiber officinale Rosc. and Capsicum frutescens L. commonly consumed in Nigeria African. J. Biotechnol. 2011, 9, 6927-6931.

65. Cardelle-Cobas, A.; Soria, A.C.; Corzo-Martinez, M.; Villamiel, M. A Comprehensive Survey of Garlic Functionality. In Garlic Consumption and Health; Pacurar, M., Karejci, G., Eds.; Nova Science Publisher: Hauppage, NY, USA, 2010 ; pp. 1-60.

66. Standard Tables of Food Composition in Japan-2015-(Seventh Revised Edition). Available online: https://www.mext.go.jp/en/ policy/science_technology/policy/title01/detail01/sdetail01/sdetail01/1385122.htm (accessed on 12 May 2021). 
67. Fratianni, F.; Ombra, M.N.; Cozzolino, A.; Riccardi, R.; Spigno, P.; Tremonte, P.; Coppola, R.; Nazzaro, F. Phenolic constituents; antioxidant; antimicrobial and anti-proliferative activities of different endemic Italian varieties of garlic (Allium sativum L.). J. Funct. Foods 2016, 21, 240-248. [CrossRef]

68. Kyureghia, G.; Flores, R. Meta-Analysis of Studies on Vitamin C Contents of Fresh and Processed Fruits and Vegetables. J. Food Nutr. Disor. 2012, 1, 2. [CrossRef]

69. Locato, V.; Cimini, S.; DeGara, L. Strategies to increase Vitamin C in plants: From plant defense perspective to food biofortification. Front. Plant Sci. 2013, 4, 152. [CrossRef] [PubMed] 